\title{
The "ABCDE" of video gaming control: Arguments, basic research, conceptual models, documented lessons, and evaluation
}

\author{
Commentary on: Policy responses to problematic video game use: A systematic \\ review of current measures and future possibilities (Király et al., 2018)
}

\author{
DANIEL T. L. SHEK*
}

Department of Applied Social Sciences, The Hong Kong Polytechnic University, Hong Kong, P. R. China

(Received: December 12, 2017; revised manuscript received: December 28, 2018; second revised manuscript received: January 7, 2019; accepted: January 13, 2019)

\begin{abstract}
This commentary responds to the review conducted by Király et al. (2018). The review enlightens and is useful in view of the limited studies on problematic use of video games and related control policies. It is argued that when considering regulation policies on video games, reference should be made to the arguments involved (A), basic research (B), conceptual models on problem video game use (C), documented lessons learning the broad field of addiction (D), and the need for rigorous evaluation (E). Besides "supply" reduction, it is vital to look at "demand" reduction in terms of how inner strengths may help to reduce the problematic use of video games.
\end{abstract}

Keywords: video game use, prevention, regulation, young people

The paper by Király et al. (2018) is an important addition to the literature for two reasons. First, most studies on addiction focus on gambling, substance abuse, and Internet addiction with few research studies on problematic video game use. Second, except the review by King et al. (2017), no known review studies have been published to understand the possible interventions to regulate video game use and reduce their negative consequences. On the whole, this is a pioneer piece of work, which triggers meaningful discussion among different stakeholders.

The review by Király et al. (2018) showed that three broad measures could be used to regulate problematic video game use. The first is to limit availability, such as shutdown, selective shutdown, fatigue system, parental controls (content filters, time limits, and monitoring), limiting the gaming time in Internet cafés, and raising the price of games. The second category of measures attempts to reduce the risks and harm, such as the use of warning messages and making the games less addictive. Finally, preventive and treatment programs and services for problematic gamers were reviewed.

In this commentary, it is proposed that when we consider controls of video games, there is a need to make reference to five issues, including: (A) arguments for and against the controls, (B) basic research on problematic video game use, (C) conceptual models, (D) documented lessons learned in the drug addiction field, and (E) evaluation of the intervention attempts to reduce addictive video gaming. In short, these are the "ABCDE" of regulating the use of video games.
The first issue to be considered is arguments (A) for controlling the use of video games. The central argument normally put forward is that because some video games lead to abuse in some children and adolescents, there is a need to control. This argument is valid in view of the negative consequences of problematic video game use in children and adolescents. Although the number of problematic video game users is small, the personal, family, and social costs can be enormous (Kuss \& Griffiths, 2012), which may justify the control. In the broadest sense, as video games can create addiction in children and adolescents, there is a need to regulate them. In a narrow sense, video games with elements of sex, violence, and/or indecent content should be regulated through mechanisms, such as Entertainment Software Rating Board and Pan European Game Information. Basically, these regulatory systems are consistent with the existing practice for television programs, movies, and printed materials where children aged under 18 years cannot get access to such materials.

However, there are several counter-arguments against the regulation on the use of video games. The first argument is that video games do not lead to addiction and problem behavior such as violence (Entertainment Software Association, 2016, 2018). Second, whether problematic video game use can be regarded as a form of mental disorder is

* Corresponding address: Daniel T. L. Shek; Department of Applied Social Sciences, The Hong Kong Polytechnic University, HJ 407, Hunghom, Hong Kong, P. R. China; Phone: +852 2766 5652; Fax: +852 2773 6546; E-mail: daniel.shek@polyu.edu.hk

This is an open-access article distributed under the terms of the Creative Commons Attribution-NonCommercial 4.0 International License, which permits unrestricted use, distribution, and reproduction in any medium for non-commercial purposes, provided the original author and source are credited, a link to the CC License is provided, and changes - if any - are indicated. 
debatable (Aarseth et al., 2017; Király \& Demetrovics, 2017; van Rooij et al., 2018; Zastrow, 2017). Third, as moderate gaming may lead to positive outcomes such as stress reduction (Männikkö, Ruotsalainen, Miettunen, Pontes, \& Kääriäinen, 2017), an excessive control of all forms of video games is debatable. Fourth, as adolescent risk behavior drops when adolescents mature (Shek \& Yu, 2016) and the addictive behaviors may be quite transient (Thege, Woodin, Hodgins, \& Williams, 2015), regulation may simply be a moral panic response. Finally, it can be argued that overcontrol of video games would limit the development of the game industry, which created an estimated global revenue of 108.9 billion in 2017 (Newzoo, 2017). Similarly, Marchand and Hennig-Thurau (2013) commented that the global revenue for video games was higher than the global revenue for music and consumer book sales. Another point that should be considered is that the governments in many countries are in fact encouraging and facilitating the development of video games (Hemels \& Goto, 2017; Storz, Riboldazzi, \& John, 2015).

The second issue is whether quality basic research (B) on video gaming exists, so that policy-makers can make wellinformed decisions on the regulation of video games. Feng, Ramo, Chan, and Bourgeois (2017) pointed out that research studies on Internet addiction outnumbered research studies on video game addiction. In addition, there are several unanswered questions on the nature and basic processes in problematic video game use. The first group of questions is concerned with the prevalence of problematic video gaming and the existence of validated measures of problematic video gaming. In a recent review of Internet gaming disorder, Feng et al. (2017) showed that problematic video gaming showed low persistence after 1 year. Furthermore, despite the rapid advance in technology and widespread use of the Internet in the 15-year review period, the prevalence of Internet gaming disorder did not change much. The authors suggested that researchers should use consistent methodology, comparable populations, clear data, and longitudinal designs and consider the cultural and social environment leading to fluctuation in future prevalence studies.

The second group of questions is related to the possible causes of problematic video gaming, such as whether personal factors (e.g., comorbidity), family factors, and social policies lead to problematic video gaming. From an intervention point of view, we must know the causes of problematic video gaming before any meaningful policies can be devised. For example, if family factors strongly account for problematic video gaming, relevant family policies and services should be devised.

Finally, there are questions surrounding the consequences of "healthy" and "unhealthy" video gaming, such as the short-term, medium-term, and long-term consequences of using video games, which determine the "gravity" of the regulation. Obviously, we have to conduct basic research to provide answers to these questions before we can formulate any evidence-based strategies to deal with the negative impacts of problematic video gaming.

The third issue surrounds the conceptual models (C) on the causes of problematic video game use. Theoretically, there are many micro- and macro-approaches to understanding addictions such as substance abuse and pathological gambling. At present, the most widely accepted model on addiction is the social-ecological model (Kliewer \& Murrelle, 2007) that outlines the influence of risk factors (which increase the probability of addiction) and protective factors (which decrease the probability of addiction). Hence, a reduction in the problematic use of video games should minimize the effects of risk factors (such as weak resilience) but maximize the effects of protective factors (such as social support).

From another angle, some researchers (European Monitoring Centre for Drugs and Drug Addiction, 2017; Pentz, Bonnie, \& Shopland, 1996; Wodak, 2011) argued that an increase in supply and/or demand would lead to addictive behavior, such as problematic video game use. Hence, it would be helpful to examine the factors leading to an increase in supply and/or demand. In the review conducted by Király et al. (2018), most of the measures concentrate on "supply" reduction, with little focus on how excessive demands for video game use arising from individual and familial problems may be prevented. In the substance abuse literature, it is documented that certain characteristics of young people, such as poor problem-solving skills, low emotional management skills, weak interpersonal competence, existential vacuum, and low family support, contribute to substance abuse (Whitesell, Bachand, Peel, \& Brown, 2013). Obviously, these findings constitute useful pointers to design measures to reduce the factors that contribute to high demand and thus indirectly to the decrease of problematic video game use.

The fourth issue is on the documented lessons (D) from the addiction literature, particularly from the field of substance abuse. In fact, while supply reduction (such as regulating the sale of sleeping pills) is important, much work has been carried out in the drug and gambling fields emphasizing demand reduction by promoting psychosocial competencies in young people. With particular reference to drug education as a preventive measure of adolescent substance abuse, several lessons from adolescent drug abuse literature can possibly be translated to problematic video game use. First, moral objection does not work as it may create guilt and frustration in young abusers (Glynn, Leukefeld, \& Ludford, 1983). Second, the fear approach does not work because it may trigger the sensationseeking motive of young people (Warren, 2016). Third, the knowledge-focused approach focusing on the purely objective facts does not work because knowledge alone may create curiosity in young people who may eventually try the drugs (Botvin \& Griffin, 2006). Finally, promotion of psychosocial competence in young people has been regarded as a promising approach to prevent youth drug addiction. In the National Registry of Evidence-Based Programs and Practices of the Substance Abuse and Mental Health Services Administration (SAMHSA, USA), evidence-based programs focusing on life skills development (e.g., Life Skills Training) can serve as useful reference for prevention programs for problematic video game use (https:/www.samhsa.gov/data/ evidence-based-programs-nrepp; SAMHSA, 2014).

Closely related to the field of adolescent prevention is another body of literature on positive youth development (PYD), which highlights the importance of social-emotional learning and psychosocial competence in young people 
(Benson, Scales, \& Syvertsen, 2011). According to this view, development of psychosocial competencies such as resilience, emotional competence, and positive identity would help to promote positive development in young people, which would eventually help them stay away from risky behavior such as problematic use of video games. For example, Shek (2017) reported that PYD programs can help to prevent drug abuse and problem behavior in adolescents in the Project P.A.T.H.S. in Hong Kong. The author suggested that the PYD approach is similar to the basic tenet of Chinese medicine of "strengthening the inner qualities" (gu ben pei yuan), through which adolescents will thrive and stay away from problem behavior when they have inner strengths. Obviously, it would be theoretically and practically exciting to see whether the protective role of PYD constructs also applies to problematic video game use.

The final issue is evaluation (E). Irrespective of the approaches and strategies for reducing problematic video gaming, there is a need to assess the impact of the implemented interventions. There are examples in the addiction field that interventions simply do not work, such as the Project D.A.R.E. (West \& O’Neal, 2004). On the other hand, there are findings showing that some intervention programs could help to reduce Internet addiction and problematic game use (Shek \& Sun, 2010; Turel, Mouttapa, \& Donato, 2015; Walther, Hanewinkel, \& Morgenstern, 2014).

There are several points that researchers should bear in mind when considering evaluation in initiatives to control the use of video games. First, there are different types of programs with different effects, including effective programs, promising programs, programs with unclear effects, ineffective programs, and programs with harmful consequences. Second, although many programs are designed with good intentions, "the road to hell is always paved with good intentions." Hence, good intention alone is not a sufficient condition for program success. Third, the impact of a program should be scrutinized with reference to the hierarchy of evidence ranging from case studies to randomized trials conducted by independent research teams. Basically, it is important to ascertain whether changes in the program participants are attributed to the intervention. Fourth, different evaluative criteria can possibly be used in evaluation, ranging from positivistic criteria in quantitative research to interpretive or constructionist criteria in qualitative research.

Fifth, although randomized control trials may be used to evaluate micro-intervention programs, it is much difficult to evaluate intervention programs involving macro-social policies where direct manipulation and creation of control groups are not easy. Sixth, intervention should be guided by research evidence. For example, research evidence shows that effective school-based preventive drug education has several attributes, such as grounding in well-articulated theories, being developmentally appropriate, focusing on psychosocial competence, use of peer leaders, focusing on experiential learning, focusing on familial and community influence, and highlighting the importance of evaluation. In the drug abuse field, there are effective examples using this approach. Finally, systematic reviews and meta-analyses play an important role in evaluating the intervention programs in addiction. For instance, Faggiano et al. (2005) and Faggiano, Minozzi, Versino, and Buscemi (2014) compared different strategies of preventive drug education and emphasized the effectiveness of the skillbased intervention approach.

Funding sources: This work was financially supported by the Project P.A.T.H.S. with the sponsorship of The Hong Kong Jockey Club Charities Trust.

Author's contribution: DTLS reviewed the literature, drafted, and finalized the manuscript.

Conflict of interest: The author declares no conflict of interest.

\section{REFERENCES}

Aarseth, E., Bean, A. M., Boonen, H., Michelle, C. C., Coulson, M., Das, D., Deleuze, J., Dunkels, E., Edman, J., Ferguson, C. J., Haagsma, M. C., Helmersson Bergmark, K., Hussain, Z., Jansz, J., Kardefelt-Winther, D., Kutner, L., Markey, P., Nielsen, R. K. L., Prause, N., Przybylski, A., Quandt, T., Schimmenti, A., Starcevic, V., Stutman, G., Van Looy, J., \& Van Rooij, A. J. (2017). Scholars' open debate paper on the World Health Organization ICD-11 Gaming Disorder proposal. Journal of Behavioral Addictions, 6(3), 267-270. doi:10.1556/2006.5.2016.088

Benson, P. L., Scales, P. C., \& Syvertsen, A. K. (2011). The contribution of the developmental assets framework to positive youth development theory and practice. In R. M. Lerner, J. V. Lerner, \& J. B. Benson (Eds.), Advances in child development and behavior (Vol. 41, pp. 197-230). New York, NY: Elsevier.

Botvin, G. J., \& Griffin, K. W. (2006). Drug abuse prevention curricula in schools. In Z. Sloboda \& W. J. Bukoski (Eds.), Handbook of drug abuse prevention: Theory, science, and practice (pp. 45-74). Boston, MA: Springer.

Entertainment Software Association. (2016). Essential facts about games and violence. Washington, DC: Entertainment Software Association.

Entertainment Software Association. (2018). ESA statement on proposed WHO video game classification. Retrieved from $\mathrm{http}: / / w w w . t h e e s a . c o m / a r t i c l e / e s a-s t a t e m e n t-p r o p o s e d-v i d e o-$ game-classification/

European Monitoring Centre for Drugs and Drug Addiction. (2017). Drug supply reduction: An overview of EU policies and measures. EMCDDA Papers, Publications Office of the European Union, Luxembourg.

Faggiano, F., Minozzi, S., Versino, E., \& Buscemi, D. (2014). Universal school-based prevention for illicit drug use. Cochrane Database of Systematic Reviews, 2014, CD003020. doi:10.1002/14651858.CD003020.pub3

Faggiano, F., Vigna-Taglianti, F. D., Versino, E., Zambon, A., Borraccino, A., \& Lemma, P. (2005). School-based prevention for illicit drugs' use. Cochrane Database of Systematic Reviews, 2005, CD003020. doi:10.1002/14651858.CD003020. pub2 
Feng, W., Ramo, D. E., Chan, S. R., \& Bourgeois, J. A. (2017). Internet gaming disorder: Trends in prevalence 1998-2016. Addictive Behaviors, 75, 17-24. doi:1016/j.addbeh.2017. 06.010

Glynn, T. J., Leukefeld, C. G., \& Ludford, J. P. (1983). Preventing adolescent drug abuse: Intervention strategies. Washington, DC: National Institute on Drug Abuse.

Hemels, S., \& Goto, K. (Eds.). (2017). Tax incentives for the creative industries. Singapore: Springer.

King, D. L., Delfabbro, P. H., Doh, Y. Y., Wu, A. M. S., Kuss, D. J., Pallesen, S., Mentzoni, R., Carragher, N., \& Sakuma, H. (2017). Policy and prevention approaches for disordered and hazardous gaming and Internet use: An international perspective. Prevention Science, 19(2), 233-249. doi:10.1007/s11121017-0813-1

Király, O., \& Demetrovics, Z. (2017). Inclusion of gaming disorder in ICD has more advantages than disadvantages. Commentary on: Scholars' open debate paper on the World Health Organization ICD-11 Gaming Disorder proposal (Aarseth et al.). Journal of Behavioral Addictions, 6(3), 280-284. doi:10.1556/ 2006.6.2017.046

Király, O., Griffiths, M. D., King, D. L., Lee, H. K., Lee, S. Y., Bányai, F., Zsila, Á., Takacs, Z. K., \& Demetrovics, Z. (2018). Policy responses to problematic video game use: A systematic review of current measures and future possibilities. Journal of Behavioral Addictions, 7(3), 503-517. doi:10.1556/2006.6. 2017.050

Kliewer, W., \& Murrelle, L. (2007). Risk and protective factors for adolescent substance use: Findings from a study in selected Central American countries. Journal of Adolescent Health, 40(5), 448-455. doi:1016/j.jadohealth.2006.11.148

Kuss, D. J., \& Griffiths, M. D. (2012). Internet gaming addiction: A systematic review of empirical research. International Journal of Mental Health and Addiction, 10(2), 278-296. doi:1007/ s11469-011-9318-5

Männikkö, N., Ruotsalainen, H., Miettunen, J., Pontes, H. M., \& Kääriäinen, M. (2017). Problematic gaming behaviour and health-related outcomes: A systematic review and metaanalysis. Journal of Health Psychology. Advance online publication. doi:10.1177/1359105317740414

Marchand, A., \& Hennig-Thurau, T. (2013). Value creation in the video game industry: Industry economics, consumer benefits, and research opportunities. Journal of Interactive Marketing, 27(3), 141-157. doi:1016/j.intmar.2013.05.001

Newzoo. (2017). Newzoo global games market report 2017: Light version. Retrieved from https://newzoo.com/insights/trendreports/newzoo-global-games-market-report-2017-light-version/

Pentz, M. A., Bonnie, R. J., \& Shopland, D. R. (1996). Integrating supply and demand reduction strategies for drug abuse prevention. American Behavioral Scientist, 39(7), 897-910. doi: $1177 / 0002764296039007010$

SAMHSA. (2014). Evidence based programs: NREPP. Retrieved from https://www.samhsa.gov/nrepp

Shek, D. T. L. (2017). Prevention of drug abuse in Chinese adolescents in Hong Kong: The role of positive youth development. In M. Israelashvili \& J. L. Romano (Eds.),
The Cambridge handbook of international prevention science (pp. 635-657). New York, NY: Cambridge University Press.

Shek, D. T. L., \& Sun, R. C. F. (2010). Effectiveness of the tier 1 program of Project P.A.T.H.S.: Findings based on three years of program implementation. TheScientificWorldJournal, 10, 1509-1519. doi:10.1100/tsw.2010.122

Shek, D. T. L., \& Yu, L. (2016). Adolescent Internet addiction in Hong Kong: Prevalence, change, and correlates. Journal of Pediatric \& Adolescent Gynecology, 29(1S), S22-S30. doi:1016/j.jpag.2015.10.005

Storz, C., Riboldazzi, F., \& John, M. (2015). Mobility and innovation: A cross-country comparison in the video games industry. Research Policy, 44(1), 121-137. doi:1016/j.respol. 2014.07.015

Thege, B. K., Woodin, E. M., Hodgins, D. C., \& Williams, R. J. (2015). Natural course of behavioral addictions: A 5-year longitudinal study. BMC Psychiatry, 15(1), 4. doi:10.1186/ s12888-015-0383-3

Turel, O., Mouttapa, M., \& Donato, E. (2015). Preventing problematic Internet use through video-based interventions: A theoretical model and empirical test. Behaviour \& Information Technology, 34(4), 349-362. doi:1080/0144929X.2014. 936041

van Rooij, A. J., Ferguson, C. J., Carras, M. C., Kardefelt-Winther, D., Shi, J., Aarseth, E., Bean, A. M., Bergmark, K. H., Brus, A., Coulson, M., Deleuze, J., Dullur, P., Dunkels, E., Edman, J., Elson, M., Etchells, P. J., Fiskaali, A., Granic, I., Jansz, J., Karlsen, F., Kaye, L. K., Kirsh, B., Lieberoth, A., Markey, P., Mills, K. L., Nielsen, R. K., Orben, A., Poulsen, A., Prause, N., Prax, P., Quandt, T., Schimmenti, A., Starcevic, V., Stutman, G., Turner, N. E., van Looy, J., \& Przybylski, A. K. (2018). A weak scientific basis for gaming disorder: Let us err on the side of caution. Journal of Behavioral Addictions, 7(1), 1-9. doi:1556/2006.7.2018.19

Walther, B., Hanewinkel, R., \& Morgenstern, M. (2014). Effects of a brief school-based media literacy intervention on digital media use in adolescents: Cluster randomized controlled trial. Cyberpsychology, Behavior, and Social Networking, 17(9), 616-623. doi:1089/cyber.2014.0173

Warren, F. (2016). 'What works' in drug education and prevention? Edinburgh, Scotland: Health and Social Care Analysis, Scottish Government.

West, S. L., \& O'Neal, K. K. (2004). Project D.A.R.E. outcome effectiveness revisited. American Journal of Public Health, 94(6), 1027-1029. doi:2105/AJPH.94.6.1027

Whitesell, M., Bachand, A., Peel, J., \& Brown, M. (2013). Familial, social, and individual factors contributing to risk for adolescent substance use. Journal of Addiction, 2013, 1-9. doi: $10.1155 / 2013 / 57931$

Wodak, A. (2011). Demand reduction and harm reduction. Geneva, Switzerland: Global Commission on Drug Policies.

Zastrow, M. (2017). News feature: Is video game addiction really an addiction? Proceedings of the National Academy of Sciences of the United States of America, 114(17), 4268-4272. doi:1073/pnas.1705077114 